\title{
CHOLESTEROL AS A NATURAL PROBE FOR FREE RADICAL-MEDIATED LIPID PEROXIDATION IN BIOLOGICAL MEMBRANES AND LIPOPROTEINS
}

\author{
Albert W. Girotti ${ }^{1 *}$ and Witold Korytowski ${ }^{1,2}$ \\ ${ }^{1}$ Department of Biochemistry, Medical College of Wisconsin, Milwaukee, WI, USA, and \\ ${ }^{2}$ Department of Biophysics, Jagiellonian University, Krakow, Poland
}

Running title: Probing Lipid Peroxidation with Radiolabeled Cholesterol

${ }^{*}$ Correspondence to:

Albert W. Girotti, Ph.D.

Department of Biochemistry

Medical College of Wisconsin

Milwaukee, WI 53226

Tel: 414-955-8432

E-mail: agirotti@mcw.edu 


\begin{abstract}
We describe a relatively convenient and reliable procedure for assessing the magnitude of free radical-mediated (chain) lipid peroxidation in biological systems. The approach is based on use of radiolabeled cholesterol $\left(\left[{ }^{14} \mathrm{C}\right] \mathrm{Ch}\right)$ as a probe and determination of well-resolved oxidation intermediates/products $\left(\left[{ }^{14} \mathrm{C}\right] \mathrm{ChOX}\right.$ species), using high performance thin layer chromatography with phorphorimaging detection (HPTLC-PI). In a lipid hydroperoxide-primed liposomal test system treated with ascorbate and a lipophilic iron chelate, the following well-resolved $\left[{ }^{14} \mathrm{C}\right] \mathrm{ChOX}$ are detected and quantified: $7 \alpha / 7 \beta-\mathrm{OOH}, 7 \alpha / 7 \beta-\mathrm{OH}$, and 5,6-epoxide, their levels increasing with incubation time at 37 ${ }^{\circ} \mathrm{C}$. $\left[{ }^{14} \mathrm{C}\right] \mathrm{Ch}$ also serves as an excellent probe for lipid peroxidation in lipoproteins and plasma membranes of mammalian cells. Because this approach utilizes $\mathrm{Ch}$ as a natural in situ probe, it eliminates potential artifacts associated with artificial probes such as spin traps and fluorophores.
\end{abstract}

Key Words: Cholesterol, cholesterol oxides, free radicals, lipid peroxidation, thin layer chromatography,

phosphorimaging 


\section{Abbreviations}

$\mathrm{AH}^{-}$: ascorbate

ALA: 5-aminolevulinic acid

Ch: cholesterol [(3ß)-cholest-5-en-3-ol)]

ChOOH: cholesterol hydroperoxide

ChOX: cholesterol oxide(s)

DFO: desferrioxamine

DMPC: 1,2-dimyristoyl-sn-glycero-3-phosphocholine

$\mathrm{Fe}(\mathrm{HQ})_{3}$ : ferric 8-hydroxyquinoline

GPx4: type-4 glutathione peroxidase

HPLC-EC $(\mathrm{Hg})$ : high-performance liquid chromatography with mercury cathode electrochemical detection HPTLC-PI: high-performance thin layer chromatography with phosphorimaging detection

LDL: low density lipoprotein

LH: unsaturated lipid

LOOH: lipid hydroperxide

PLOOH: phospholipid hydroperoxide

POPC: 1-palmitoyl-2-oleoyl-sn-glycero-3-phosphocholine

SPNO: spermine NONOate

SUV/LUV: small and large unilamellar vesicles (liposomes)

5a-OOH: 3ß-hydroxy-5a-cholest-6-ene-5-hydroperoxide

5a-OH: 5a-cholest-6-ene-3ß,5-diol

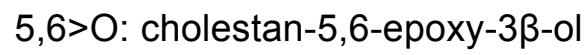

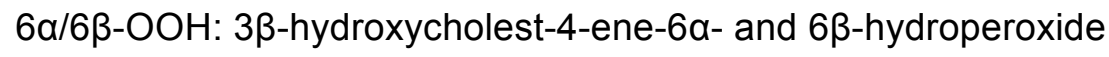

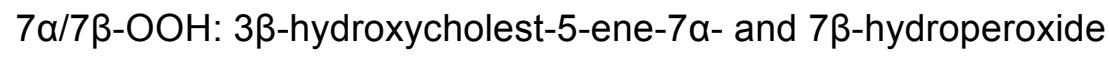

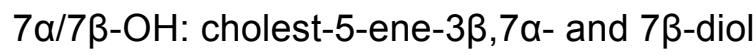


7=0: 3ß-hydroxycholest-5-ene-7-one

\section{Introduction}

Oxidative stress-induced peroxidation of unsaturated phospholipids and cholesterol in cell membranes and lipoproteins is of considerable biomedical interest because of its possible involvement in pathophysiological conditions such as chronic inflammation, ischemia-reperfusion injury, neurodegeneration, and atherogenesis [1-4]. Oxidative stress arising when pro-oxidant pressure exceeds antioxidant capacity is accompanied by formation of reactive oxygen species (ROS) such as superoxide $\left(\mathrm{O}_{2}^{-}\right)$, hydrogen peroxide $\left(\mathrm{H}_{2} \mathrm{O}_{2}\right)$, and hydroxyl radical $(\mathrm{HO} \cdot)$, the latter being a strong indiscriminate oxidant that can initiate non-enzymatic free radical-mediated lipid peroxidation [3]. The initiating step might be abstraction of an allylic hydrogen from an unsaturated sn-2 fatty acyl group on a membrane phospholipid, e.g. 1 palmitoyl-2-linoleoyl-sn-glycero-phosphocholine (PLPC); see Eq. 1,

$$
\begin{aligned}
& \mathrm{LH}+\mathrm{HO} \cdot \rightarrow \mathrm{L} \cdot+\mathrm{H}_{2} \mathrm{O} \\
& \mathrm{L} \cdot+\mathrm{O}_{2} \rightarrow \mathrm{LOO} \cdot \\
& \mathrm{LOO}+\text { + L'H } \rightarrow \mathrm{LOOH}+\mathrm{L}^{\prime} \cdot \\
& \mathrm{LOOH}+\mathrm{Fe}^{2+}+\mathrm{O}_{2} \rightarrow \mathrm{OLOO}+\mathrm{OH}^{-}+\mathrm{Fe}^{3+} \\
& \text { OLOO + L"H } \rightarrow \text { OLOOH + L". } \\
& \mathrm{OLOOH}+\mathrm{Fe}^{2+} \rightarrow \mathrm{OLO} \cdot+\mathrm{OH}^{-}+\mathrm{Fe}^{3+} \\
& \mathrm{OLO}+\text { + L"'H } \rightarrow \mathrm{OLOH}+\mathrm{L} \text { "'. }
\end{aligned}
$$

where $\mathrm{LH}$ denotes an unsaturated lipid. The resulting alkyl radical $(\mathrm{L} \cdot)$ reacts rapidly with $\mathrm{O}_{2}$ to give a peroxyl radical (LOO·) (Eq. 2), which in turn can abstract an allylic hydrogen from another unsaturated lipid ( $\mathrm{L}$ 'H), giving a lipid hydroperoxide $(\mathrm{LOOH})(\mathrm{Eq} .3)$. The accompanying L'. then begins the propagative phase of chain peroxidation (Eqs. 2 and 3). Meanwhile, if suitably ligated iron (or other redox metal ion) and a reductant are available, $\mathrm{LOOH}$ can undergo one-electron reduction to an oxyl radical (LO·), which rearranges and reacts with $\mathrm{O}_{2}$ to give an epoxyallylic peroxyl radical (OLOO·) (Eq. 4) [5]. The latter in turn can induce a new round of chain peroxidation via hydrogen abstraction from another proximal lipid (Eq. 5). The resulting hydroperoxide may also undergo iron-catalyzed one- 
electron reduction (Eq. 6), triggering a new chain via OLO, which is reduced to an alcohol (Eq. 7). LOOHs can also arise in non-radical fashion, a key example being "ene" addition of singlet molecular oxygen $\left({ }^{1} \mathrm{O}_{2}\right)$, a photochemically-generated ROS, to an unsaturated lipid [4]. However, subsequent oneelectron turnover of ${ }^{1} \mathrm{O}_{2}$-derived $\mathrm{LOOHs}$ can induce chain peroxidation reactions (Eqs. 4-7) similar to those initiated by $\mathrm{HO} \cdot[2-4]$.

Non-esterified cholesterol $(\mathrm{Ch})$ is found in the outer layer of lipoproteins and in membranes of eukaryotic cells, most of it residing in the plasma membrane, where it comprises $\sim 45 \mathrm{~mol} \%$ of total lipid. As a monounsaturated lipid, $\mathrm{Ch}$ is susceptible to oxidative degradation, but less so than polyunsaturated fatty acyl groups in phospholipids. Oxidation occurring in the ring portion of $\mathrm{Ch}$ is predominantly non-enzymatic (free radical-mediated), whereas that occurring in the side-chain is usually enzymatic [6]. Free radical-mediated oxidation gives rise to a discrete number of cholesterol oxides (oxysterols), including hydroperoxides (ChOOHs), diols, epoxides, and ketone [6-8]. A lipid peroxyl radical can attack at the Ch double bond, giving epimeric 5,6-epoxides $(5,6>0)$ (Eq. 8).

$$
\begin{aligned}
& \mathrm{Ch}+\mathrm{OLOO} \rightarrow 5,6>\mathrm{O}+\mathrm{OLO} \cdot \\
& \mathrm{Ch}+\mathrm{OLOO} \cdot 7 \cdot+\mathrm{OLOOH} \\
& 7 \cdot+\mathrm{O}_{2} \rightarrow 7-\mathrm{OO} \cdot \\
& 7-\mathrm{OO}+\mathrm{LH} \rightarrow 7-\mathrm{OOH}+\mathrm{L}^{\prime} \\
& 7-\mathrm{OOH}+\mathrm{Fe}^{2+} \rightarrow 7-\mathrm{O} \cdot+\mathrm{OH}^{-}+\mathrm{Fe}^{3+} \\
& 7-\mathrm{O} \cdot+\mathrm{L}^{\prime} \mathrm{H} \rightarrow 7-\mathrm{OH}+\mathrm{L}^{\prime} \cdot \\
& 7-\mathrm{O} \cdot+\mathrm{OLOO} \cdot \rightarrow 7=\mathrm{O}+\mathrm{OLOOH}
\end{aligned}
$$

Alternatively, abstraction of a C-7 allylic hydrogen by a strong oxidant such as OLOO-, followed by $\mathrm{O}_{2}$ addition and hydrogen abstraction from another lipid gives the $7 \alpha$ - and $7 \beta$-hydroperoxides $(7-\mathrm{OOHs})$ (Eqs. 9-11). As with LOOHs in general, iron-catalyzed one-electron reduction of either 7-OOH gives the corresponding diol (7-OH) (Eqs. 12 and 13). Alternatively, the oxyl radical intermediate may undergo $\beta$ hydrogen scission in the presence of a peroxyl radical, giving the 7-ketone $(7=0)$ (Eq. 14). Structures of the Ch oxides (ChOX) referred to in Eqs. 8-14, and which are prominent in the analytical approach we describe, are shown in Fig. 1. It is important to note that whereas $7 \alpha-$ and $7 \beta-O O H$ derive 
from free radical reactions, $5 \alpha-\mathrm{OOH}$ and $6 \alpha / 6 \beta-\mathrm{OOH}$ are generated exclusively by ${ }^{1} \mathrm{O}_{2}$ attack on $\mathrm{Ch}$ and can serve as unambiguous reporters of ${ }^{1} \mathrm{O}_{2}$ intermediacy in membrane oxidations $[4,7,9]$.

Ongoing interest in free radical-mediated lipid peroxidation has stimulated the development of highly sensitive and specific techniques for detecting and quantifying this process. These techniques typically involve measurement of reactive intermediates such as hydroperoxides or end-products such as hydroxides and aldehydes. They range from relatively simple "bulk-type" methods, e.g. the classic thiobarbituric acid and iodometric assays [9] to more sophisticated methods involving high performance liquid or gas chromatography with high sensitivity/specificity post-column detection of LOOHs and other characteristic species [10-12]. Perceiving the need for more convenience and less complexity in monitoring chain lipid peroxidation, the authors introduced a novel approach based on use of radiolabeled $\mathrm{Ch}$ as a natural probe for free radical lipid peroxidation in biological membranes and lipoproteins [13]. In this approach, $\left[{ }^{14} \mathrm{C}\right] \mathrm{Ch}$ acts as a "sensor" of free radical activity in its surroundings. The intermediates and products of $\left[{ }^{14} \mathrm{C}\right] \mathrm{Ch}$ oxidation, $\left(\left[{ }^{14} \mathrm{C}\right] \mathrm{ChOX}\right.$ species $)$ serve as reporters of damaging peroxidation and are detected by high-performance thin layer chromatography with phosphorimaging (HPTLC-PI). We describe several different protocols that illustrate how this unique approach can be used to detect/quantify chain peroxidation in a variety of test systems ranging from relatively simple liposomes to mammalian cells. A simplified procedural flow diagram for determination of $\left[{ }^{14} \mathrm{C}\right] \mathrm{ChOX}$ species in oxidatively stressed cells is shown in Scheme 1.

\section{Materials}

\subsection{Chemicals and reagents}

All chemicals and reagents should be of the highest purity available. Unlabeled $\mathrm{Ch}, 7 \alpha-\mathrm{OH}, 7=\mathrm{O}$, Chelex-100, desferrioxamine, 8-hydroxyquinoline, ascorbic acid, fetal bovine serum, cell growth media, and media supplements are available from Sigma Chemical Co. (St. Louis, MO). $\left[4-{ }^{14} \mathrm{C}\right] \mathrm{Ch}(\sim 50 \mathrm{mCi} / \mathrm{ml}$ in toluene) is obtained from Amersham Life Sciences (Arlington Heights, IL). 1-palmitoyl-2-oleoyl-snglycero-3-phosphocholine (POPC) and 1,2-dimyristoyl-sn-glycero-3-phosphocholine (DMPC) are obtained from Avanti Polar Lipids (Birmingham, $\mathrm{AL}$ ) and 5,6>0 from Steraloids (Wilton, NH). Mobile 
phases for TLC separations are prepared using HPLC-grade solvents. $5 \alpha-O O H$ and $7 \alpha-O O H$, which are not commercially available, are prepared by dye-sensitized photoperoxidation of Ch in pyridine or in liposomal form $[9,12]$. The hydroperoxides are isolated by reverse-phase HPLC, subsequent normalphase HPLC being used to separate $7 \alpha-\mathrm{OOH}$ from any $7 \beta-\mathrm{OOH}[11,12]$. After confirmation of identity by proton NMR [14], $5 \alpha-\mathrm{OOH}$ and $7 \alpha-\mathrm{OOH}$ are stored in isopropanol at $-20{ }^{\circ} \mathrm{C}$. Immediately before experiments, peroxide levels of $\mathrm{ChOOH}$ preparations are determined by iodometric analysis [9]. Ultrapure Millipore quality water is used for all aqueous solutions. Before use, buffer solutions are treated with Chelex-100 to deplete redox metal ions such as $\mathrm{Fe}^{3+}$ and $\mathrm{Cu}^{2+}$.

\subsection{Liposomes}

Unilamellar liposomes suitable for initial experiments are prepared by an extrusion process using a device from Lipex Biomembranes (Vancouver, BC, Canada) with polycarbonate filters of requisite pore size [15]. Small vesicles (SUVs) or large vesicles (LUVs) of $50 \mathrm{~nm}$ or $100 \mathrm{~nm}$ average diameter, respectively, can be used. Before incorporation into liposomes, $\left[{ }^{14} \mathrm{C}\right] \mathrm{Ch}(1-2 \mu \mathrm{Ci})$ plus unlabeled carrier is separated from any preexisting oxides by TLC (see below). The major band of Ch is detected by radioscanning, recovered by scraping, eluted with chloroform/methanol $(2 / 1 \mathrm{v} / \mathrm{v})$, dried under $\mathrm{N}_{2}$, and stored at $-20{ }^{\circ} \mathrm{C}$. For a typical experiment in which chain-initiating potency of a $\mathrm{ChOOH}$ is to be evaluated, one can use LUVs consisting of $1.0 \mathrm{mM}$ POPC, $0.75 \mathrm{mM}\left[{ }^{14} \mathrm{C}\right] \mathrm{Ch}(0.5-1.0 \mu \mathrm{Ci} / \mathrm{ml})$, and 0.05 $\mathrm{mM} \mathrm{ChOOH}(5 \alpha-\mathrm{OOH}$ or $7 \mathrm{a}-\mathrm{OOH})$ in bulk aqueous phase. Initial ChOOH content of these LUVs ( 3 mol \%) models that of a natural plasma membrane subjected to some basal oxidative stress [13]. A suitable aqueous medium is phosphate buffered saline (pH 7.4 PBS) pre-treated with Chelex-100 to deplete redox metal ions; the latter might otherwise catalyze $\mathrm{ChOOH}$ decomposition. Liposomes are stored under argon at $4{ }^{\circ} \mathrm{C}$ and typically used for experiments within $48 \mathrm{~h}$ after preparation.

\subsection{Low density lipoprotein}

Whole plasma is prepared from freshly drawn blood provided by a local blood bank. The low density lipoprotein (LDL) fraction (density $1.019-1.063 \mathrm{~g} / \mathrm{mL}$ ) is isolated by flotation ultracentrifugation in $\mathrm{KBr}$, as described [16]. All preparative solutions are dialyzed against Chelex-100 and sparged with argon 
before use. Immediately after harvesting, the LDL is dialyzed against argon-sparged PBS/DFO/EDTA, stored under argon at $4{ }^{\circ} \mathrm{C}$, and used experimentally within one week. Preparations are standardized according to ApoB-100 protein content. In preparation for assessing endogenous chain peroxidation via $\left[{ }^{14} \mathrm{C}\right] \mathrm{ChOX}$ formation, LDL is labeled with $\left[{ }^{14} \mathrm{C}\right] \mathrm{Ch}$ using agarose-conjugated $\mathrm{BSA}$ as an easily removable vehicle $[17,18]$. A $1 \mathrm{~mL}$ aliquot of $B S A$ solution $(10 \mathrm{mg} / \mathrm{mL}$ in PBS/DFO) is added to $1 \mathrm{~mL}$ of PBS-washed Affi-Gel agarose beads (Bio-Rad, Richmond, CA). The slurry is gently mixed for $1 \mathrm{~h}$ at $37^{\circ} \mathrm{C}$, after which the BSA-linked beads are washed with PBS to remove unbound protein and then sparged with argon. A $50 \mu$ laliquot of $\left[{ }^{14} \mathrm{C}\right] \mathrm{Ch}(\sim 1 \mu \mathrm{Ci})$ in acetone is added, followed by $4 \mathrm{~h}$ of slow mixing at $37{ }^{\circ} \mathrm{C}$ under argon. The $\left[{ }^{14} \mathrm{C}\right] \mathrm{Ch}$-charged BSA beads are then washed with and resuspended in PBS/DFO. To a $1 \mathrm{~mL}$ portion of the slurry is added $1 \mathrm{~mL}$ of stock LDL (2 $\mathrm{mg}$ protein/mL), followed by further incubation for $1 \mathrm{~h}$ under argon with gentle agitation. The $\left[{ }^{14} \mathrm{C}\right] \mathrm{Ch}$-labeling efficiency for LDL is typically $>50 \%$, as determined by scintillation counting.

\subsection{Isolated erythrocyte membranes}

Erythrocyte membranes (white ghosts) are prepared from freshly drawn human blood in $2 \mathrm{mM}$ EDTA. Red blood cells are pelleted, washed several times with PBS, then lysed with at least 50 volumes of ice-cold $5 \mathrm{mM}$ sodium phosphate/1 mM EDTA ( $\mathrm{pH}$ 8.0). After pelleting and washing thoroughly with this buffer, the membranes are resuspended in PBS containing DFO and EDTA (100 $\mu \mathrm{M}$ each) and stored at $4{ }^{\circ} \mathrm{C}$ for no longer than one week. Membranes prepared in this way are sufficiently depleted of redox iron so as to minimize any $\mathrm{LOOH}$ formation/turnover during $\mathrm{LOOH}$ transfer to LDL [18]. Isolated ghost membranes are "primed" with ChOOHs and phospholipid counterparts (PLOOHs) by means of photosensitized oxidation, using a ${ }^{1} \mathrm{O}_{2}$-generating sensitizer such as aluminum phthalocyanine disulfonate $\left(\mathrm{AIPcS}_{2}\right)$ [9]. A typical reaction mixture in PBS/DFO consists of membranes (1.0 mg protein $/ \mathrm{ml}$ or $\sim 0.9 \mathrm{mg} \mathrm{lipid} / \mathrm{ml}$ ) and $25 \mu \mathrm{M} \mathrm{AIPCS}{ }_{2}$ in a thermostatted beaker at 25 ${ }^{\circ} \mathrm{C}$. The mixture is irradiated from above using a $90-\mathrm{W}$ quartz-halogen source with slow magnetic stirring. A light fluence of $180 \mathrm{~J} / \mathrm{cm}^{2}(\sim 20$ min of irradiation) produces $\sim 45 \mu \mathrm{M}$ total $\mathrm{ChOOH}$ and $\sim 165$ $\mu \mathrm{M}$ PLOOH in bulk suspension [18]. 


\subsection{Cultured mammalian cells}

Experiments can be carried out with any cell line that is susceptible to deleterious free radical lipid peroxidation. COH-BR1 cells, an epithelial subline derived from a human breast tumor [19], is represented here as a special example. Wild type $\mathrm{COH}-\mathrm{BR} 1$ cells are severely deficient in glutathione peroxidase type-4 (GPx4), the only enzyme known to catalyze two-electron reductive detoxification of ChOOHs as well as PLOOHs [20]. This deficiency is known to make these cells hypersensitive to damaging lipid peroxidation [21]. A transfectant $\mathrm{COH}-\mathrm{BR} 1$ clone overexpressing mitochondrial GPx4 is also represented for comparing cell susceptibility to toxic peroxidation under oxidative stress. Cells are grown under standard culture conditions (95\% air/5\% $\left.\quad \mathrm{CO}_{2}, \quad 37{ }^{\circ} \mathrm{C}\right)$, using DME/F12 medium supplemented with $10 \%$ fetal bovine serum and antibiotics as described [21]. Experiments are carried out on cells at $\sim 80 \%$ confluency in $10-\mathrm{cm}$ culture dishes.

\section{Protocols}

\subsection{Protocol 1: Chain peroxidation in liposomes with pre-existing $\mathrm{LOOH}(5 \alpha-\mathrm{OOH})$}

POPC $/\left[{ }^{14} \mathrm{C}\right] \mathrm{Ch} / 5 \alpha-\mathrm{OOH}(1.0: 0.75: 0.05$ by mol) LUVs $(1.8 \mathrm{mM}$ total lipid) in PBS are pre-incubated for $\sim 5 \mathrm{~min}$ with a lipophilic iron chelate, ferric-8-hydroxyquinoline $\left[\mathrm{Fe}(\mathrm{HQ})_{3}\right]$, typically at $1-2 \mu \mathrm{M}$. The reductant ascorbate $\left(\mathrm{AH}^{-}\right)$is then introduced at a starting concentration of $1 \mathrm{mM}$ to initiate the ironcatalyzed one-electron reduction of the priming hydroperoxide. Ascorbate derives from a stock $100 \mathrm{mM}$ ascorbic acid solution in PBS prepared immediately before the experiment. Reaction mixtures along with controls lacking $\mathrm{Fe}(\mathrm{HQ})_{3}$ or $\mathrm{AH}^{-}$are incubated at $37^{\circ} \mathrm{C}$ with gentle stirring. At various time points, $50 \mu \mathrm{l}$ samples are removed, mixed with $1 \mu \mathrm{l}$ of $25 \mathrm{mM}$ EDTA plus $0.2 \mathrm{ml}$ of PBS and extracted with 0.4 $\mathrm{ml}$ of cold chloroform/methanol $(2: 1 \mathrm{v} / \mathrm{v})$. After centrifugation, a $0.2 \mathrm{ml}$ aliquot from each lower phase is recovered for $\left[{ }^{14} \mathrm{C}\right] \mathrm{ChOX}$ analysis by HPTLC-PI.

High-performance silica gel-60 TLC plates $(10 \mathrm{~cm} \times 10 \mathrm{~cm}, 0.2 \mathrm{~mm}$ thickness $)$ are obtained from EM Science (Gibbstown, NJ). Samples in a hexane/2-propanol mixture $(97: 3, \mathrm{v} / \mathrm{v})$ are applied to a plate in a hairline nitrogen stream, using a programmable Linomat IV dispenser from Camag Scientific

(Wilmington, NC). Chromatography is performed in a $9 \mathrm{~cm} \times 20 \mathrm{~cm} \times 24 \mathrm{~cm}$ glass chamber, using 
benzene/ethyl acetate $(1: 1, \mathrm{v} / \mathrm{v})$ as the mobile phase. Analyte assignments are based on positions of ${ }^{14} \mathrm{C}$-labeled standards (e.g. $\left.\left[{ }^{14} \mathrm{C}\right] 7 \alpha / \beta-\mathrm{OOH},\left[{ }^{14} \mathrm{C}\right] 7 \alpha / \beta-\mathrm{OH}\right)$ chromatographed alongside. The typical running time at room temperature is $8-10 \mathrm{~min}$. After air-drying, plates are analyzed for $\left[{ }^{14} \mathrm{C}\right] \mathrm{ChOX}$ using a storage phosphor system, e.g. the Storm-860 system with ImageQuant 4.2 software (Molecular Dynamics, Sunnyvale, CA) [13]. The development time for a phosphor screen is typically $48 \mathrm{~h}$ at room temperature. For the indicated specific radioactivity of liposomal $\left[{ }^{14} \mathrm{C}\right] \mathrm{Ch}$ (see Sect. 2.2), the detection limit for $\left[{ }^{14} \mathrm{C}\right] 7 \alpha / \beta-\mathrm{OH}$, for example, is $\sim 5$ pmol. Parent $\left[{ }^{14} \mathrm{C}\right] \mathrm{Ch}$, which is depleted by $<5 \%$ in chain reactions and is well-resolved from $\left[{ }^{14} \mathrm{C}\right] \mathrm{ChOX}$ species, can be used as a reliable internal standard to correct for any loading discrepancies [13].

\subsection{Protocol 2: Chain peroxidation in photoperoxidized liposomes}

Chain peroxidation can also be studied in liposomes that are being primed with LOOHs via photosensitized peroxidation of resident lipids. For example, POPC/ $\left[{ }^{14} \mathrm{C}\right] \mathrm{Ch}(1.0: 0.8$ by mol) LUVs in a thermostatted beaker at $37^{\circ} \mathrm{C}$ are sensitized with $\mathrm{AlPcS}_{2}$ or protoporphyrin IX (PpIX) and irradiated for 45-60 min using a 90-W quartz halogen source positioned above the beaker. Irradiation is carried out in the presence of $\mathrm{AH}^{-}(1 \mathrm{mM})$ and $\mathrm{Fe}(\mathrm{HQ})_{3}(1 \mu \mathrm{M})$ or absence of either as a control. The effect of a chain-breaking antioxidant such as nitric oxide (NO) can be examined by including a chemical NO donor such as spermine-NONOate (SPNO) before irradiation. Lipids in reaction and control samples are extracted and analyzed for $\left[{ }^{14} \mathrm{C}\right] \mathrm{ChOX}$ levels as described in Sect. 3.1.

\subsection{Protocol 3: Chain peroxidation in LDL with transfer-acquired LOOHs}

Erythrocytes carry $\mathrm{O}_{2}$ in the blood circulation and are more susceptible to oxidative modification than most other cells. LOOHs generated in erythrocyte membranes can be translocated to acceptors such as LDL, where LOOH-initiated chain peroxidation may take place [18]. The resulting oxidized LDL could play a crucial role in formation of atherosclerotic plaques in the artery wall. Translocation of LOOHs from erythrocyte membranes to LDL is example of a general LOOH transfer phenomenon discovered in the authors' laboratory $[22,23]$. One can examine the susceptibility of LDL to peroxidative damage from transfer-acquired erythrocyte LOOHs by incubating $\left[{ }^{14} \mathrm{C}\right] \mathrm{Ch}$-labeled LDL with 
photoperoxidized erythrocyte ghosts for $90 \mathrm{~min}$ in argon-sparged PBS at $37^{\circ} \mathrm{C}$, using gentle magnetic stirring throughout. LOOH levels in the peroxidized ghosts are determined by iodometric assay (total $\mathrm{LOOH})$ or by HPLC-EC(Hg) for discrete LOOH classes [9]. Reaction mixture concentrations such as the following are appropriate: LDL (2-3 mM total lipid; 1 $\mu \mathrm{Ci} / \mathrm{ml})$; ghosts (50-60 $\mu \mathrm{M}$ PLOOH; $15-20 \mu \mathrm{M}$ $\mathrm{ChOOH}$ ). A control with non-peroxidized ghosts is run alongside. At various time intervals, samples are recovered, centrifuged to remove ghosts, and LDL in the supernatant fractions is incubated with prooxidant $\mathrm{Cu}^{2+}$ (e.g. 10-20 $\mu \mathrm{M} \mathrm{CuCl}$ ) to evaluate enhanced sensitivity to chain peroxidation, as determined by $\left[{ }^{14} \mathrm{C}\right] \mathrm{ChOX}$ analysis (see Sect. 3.1).

\subsection{Protocol 4: Chain peroxidation in mammalian cells}

Translocated or photogenerated LOOHs, even at relatively low starting levels, can also induce toxic bursts of chain peroxidation in living cells and these can be attenuated by chain-breaking antioxidants, including NO, which can intercept oxyl and peroxyl radicals [24,25]. One can demonstrate this by first labeling cells (e.g. sub-confluent $\mathrm{COH}-\mathrm{BR} 1$ cells in $10-\mathrm{cm}$ dishes) with $\left[{ }^{14} \mathrm{C}\right] \mathrm{Ch}$ via incubation with a $\left[{ }^{14} \mathrm{C}\right] \mathrm{Ch} /$ serum albumin complex $(1: 15 \mathrm{~mol} / \mathrm{mol})$ as described [18], followed by washing to remove loosely associated sterol. Most of the bound sterol resides in the plasma membrane, allowing chain peroxidation to be probed with high sensitivity and selectivity in this compartment. Cells may then be metabolically photosensitized with PpIX via dark incubation with its precursor, 5-aminolevulinic acid (ALA), using a procedure that allows most of the sensitizer to diffuse to plasma membrane [26]. Following this, cells are treated with $\mathrm{Fe}(\mathrm{HQ})_{3}(1-2 \mu \mathrm{M})$, then irradiated in the absence or presence of SPNO (0.2-0.4 mM), added immediately before irradiation. After $1 \mathrm{~h}$ of dark incubation, lipids are extracted and analyzed for $\left[{ }^{14} \mathrm{C}\right] \mathrm{ChOX}$ levels (see Sect. 3.1). Effects of SPNO-derived NO on ChOX accumulation are evaluated.

One can also use $\left[{ }^{14} \mathrm{C}\right] \mathrm{ChOX}$ analysis to determine ability of a mammalian enzymatic antioxidant, viz. selenoperoxidase GPx4, to protect cells against peroxidative toxicity. A vector control of wild type (GPx4-deficient) COH-BR1 cells and a mitochondrial GPx4 transfectant clone (6G4) exhibiting 160-

times greater activity are compared for ability to defend against an SUV-ChOOH challenge. After 
plasma membrane labeling with $\left[{ }^{14} \mathrm{C}\right] \mathrm{Ch}$, both cell types are incubated in the presence of DMPC/Ch/7a$\mathrm{OOH}(1.0: 0.5: 0.3$ by mol) SUVs, DMPC/Ch (1.0:0.8 by mol) SUVs serving as a control. After various incubation times, cells are washed, harvested, and extracted, the lipid fractions being analyzed for $\left[{ }^{14} \mathrm{C}\right]$ ChOX by HPTLC-PI.

\section{Expected Results}

\subsection{Application 1: Chain peroxidation in 5 $\mathrm{\alpha}-\mathrm{OOH}$-primed liposomes}

Results of a relatively simple experiment illustrating LOOH-stimulated ChOX formation in liposomal membranes are shown in Fig. 2 [25]. In this example, POPC LUVs were labeled with $\left[{ }^{14} \mathrm{C}\right] \mathrm{Ch}$ and "primed" with $5 \alpha-\mathrm{OOH}$. At time zero, $>99 \%$ of the radioactivity resided in the Ch band, which migrated well ahead of any oxides. The LUVs underwent chain peroxidation during incubation with $\mathrm{Fe}(\mathrm{HQ})_{3}$ and $\mathrm{AH}^{-}$, as indicated by the time-dependent accumulation of radiolabeled $7 \alpha / 7 \beta-\mathrm{OOH}, 7 \alpha / \beta-\mathrm{OH}$, and $5,6>0$ over at least $20 \mathrm{~min}$ (Fig. 2A). $7=0$ is not seen because it co-migrates with more abundant $5,6>0$. Whereas the $7 \alpha / 7 \beta-\mathrm{OOH}$ levels peaked at $\sim 20 \mathrm{~min}$, the $7 \alpha / 7 \beta-\mathrm{OH}$, and $5,6>0$ levels continued to rise through at least $45 \mathrm{~min}$ (Fig. 2B). Like $5 \alpha-\mathrm{OOH}, 7 \alpha / 7 \beta-\mathrm{OOH}$ are susceptible to one-electron reductive turnover, which explains their rise to an apparent steady state maximum near 20 min, followed by a decline. The higher level of $7 \beta-\mathrm{OOH}$ than $7 \alpha-\mathrm{OOH}$ throughout probably reflects the greater thermodynamic stability of $7 \beta-\mathrm{OOH}[27]$.

It is important to point out that some $\mathrm{ChOOHs}$ have only a limited ability to initiate chain peroxidation. This was discovered when free radical-generated $7 \alpha-O O H$ was compared with ${ }^{1} \mathrm{O}_{2-}$ generated $5 \alpha-\mathrm{OOH}$ and $6 \beta-\mathrm{OOH}$ [28]. All three $\mathrm{ChOOHs}$ in liposomal form were found to decay at the same rate when incubated with $\mathrm{Fe}(\mathrm{HQ})_{3}$ and $\mathrm{AH}^{-}$. Moreover, $5 \alpha-\mathrm{OOH}$ and $7 \alpha-\mathrm{OOH}$ produced $\left[{ }^{14} \mathrm{C}\right] \mathrm{ChOX}$ at an equal rate. However, under the same reaction conditions (including starting hydroperoxide concentration), $6 \beta-\mathrm{OOH}$ produced $<5 \%$ of the $\left[{ }^{14} \mathrm{C}\right] \mathrm{ChOX}$ generated by $5 \alpha-\mathrm{OOH}$ or $7 \alpha-$ $\mathrm{OOH}$ [28]. Correspondingly, $5 \mathrm{a}-\mathrm{OOH}$ and $7 \mathrm{a}-\mathrm{OOH}$ were each $\sim 50$-times more toxic to leukemia cells than $6 \beta-\mathrm{OOH}$. Since all three $\mathrm{ChOOHs}$ appeared to undergo one-electron reduction to oxyl radicals at 
equal rates, it was deduced that (a) the $6 \beta$-oxyl radical might be poorly oxidizing compared with $5 \alpha$-oxyl or $7 \alpha$-oxyl radical, i.e. the redox potential of $6 \beta$-oxyl radical might be significantly lower, or (b) $6 \beta$-oxyl radical might be kinetically restrained from initiating chains due to some structural disorientation in the membrane [28]. Which of these two alternatives may be correct remains to be established.

\subsection{Application 2: LOOH free radical turnover in photoperoxidized liposomes}

A somewhat more complex scenario involves $\left[{ }^{14} \mathrm{C}\right] \mathrm{Ch}$-containing LUVs in which LOOHs are generated de novo by PpIX-sensitized photooxidation and undergo immediate one-electron reduction in the presence of $\mathrm{Fe}(\mathrm{HQ})_{3}$ and $\mathrm{AH}^{-}$[29]. As shown in Fig. 3A, several $\left[{ }^{14} \mathrm{C}\right] \mathrm{ChOX}$ appear under these conditions including $\mathrm{ChOOHs}(5 \alpha-\mathrm{OOH}, 6 \alpha / \beta-\mathrm{OOH}, 7 \alpha / \beta-\mathrm{OOH}$ - some only partially resolved) along with well-resolved $5 \alpha-\mathrm{OH}, 7 \alpha-\mathrm{OH}, 7 \beta-\mathrm{OH}$, and $6 \beta-\mathrm{OH} .7 \alpha-\mathrm{OH}$ and $7 \beta-\mathrm{OH}$ levels were substantially diminished when photooxidation was carried out in the presence of SPNO (Fig. 3A,C), consistent with NO scavenging of free radical intermediates [24,25,29]. However, $5 \alpha-\mathrm{OH}$ and $6 \beta-\mathrm{OH}$ levels were

unchanged (Fig. 3A,B), indicating that neither rapid photogeneration of primary ChOOHs nor iron reduction had been affected by NO at the level generated in this system.

\subsection{Application 3: Free radical turnover of transfer-acquired LOOHs in LDL}

A third illustration involves priming an acceptor system, viz. $\left[{ }^{14} \mathrm{C}\right] \mathrm{Ch}$-labeled LDL, via spontaneous $\mathrm{LOOH}$ translocation from a donor system, viz. photooxidized erythrocyte ghost membranes [18]. HPTLC-PI profiles depicting $\left[{ }^{14} \mathrm{C}\right] \mathrm{ChOX}$ accumulation in the LDL after $0,1,1.5$, and $4 \mathrm{~h}$ of incubation with $\mathrm{Cu}^{2+}$ are shown in Fig. 4A. System a represents control LDL (pre-incubated with nonphotooxidized ghosts) and System $b$ experimental LDL (pre-incubated with photooxidized ghosts). Initial total $\mathrm{LOOH}$ (predominantly $\mathrm{PLOOH}$ plus $\mathrm{ChOOH}$ ) in the experimental LDL was $\sim 4.6 \mu \mathrm{M}$ in bulk suspension, whereas LOOH in control LDL was $<25 \mathrm{nM}$. Five $\left[{ }^{14} \mathrm{C}\right] \mathrm{ChOX}$ species are identified which intensify over time: $7 \alpha-\mathrm{OH}, 7 \beta-\mathrm{OH}, 5,6>0$, and partially resolved $7 \alpha$ - and $7 \beta-\mathrm{OOH}$. Importantly, the ChOX appeared earlier in System $b$ and System $a$, suggesting more rapid and greater free radical activity in the former [18]. ChOX kinetic plots B (Fig. 4B) confirm this point, showing a 30-min longer lag period in System a than in System $b$, whereas post-lag accumulation rates were the same. 


\subsection{Application 4: Lipid chain peroxidation in mammalian cells: inhibition by NO}

$\left[{ }^{14} \mathrm{C}\right] \mathrm{Ch}$ can also be used to monitor free radical peroxidation in plasma membranes of living cells. Figure 5 shows results of such an experiment in which $\left[{ }^{14} \mathrm{C}\right] \mathrm{Ch}$-labeled $\mathrm{COH}-\mathrm{BR} 1$ breast tumor cells were subjected to a specific type PpIX-sensitized $\left({ }^{1} \mathrm{O}_{2}\right.$-mediated) photooxidation that resulted in primary $\mathrm{LOOH}$ generation mainly in the plasma membrane [26], where most of the $\left[{ }^{14} \mathrm{C}\right] \mathrm{Ch}$ was located. This generation strongly stimulated $\left[{ }^{14} \mathrm{C}\right] \mathrm{ChOX}$ formation and this was further enhanced by $\mathrm{Fe}(\mathrm{HQ})_{3}$. On the other hand, SPNO added immediately before irradiation reduced all $\left[{ }^{14} \mathrm{C}\right] \mathrm{ChOX}$ levels (Fig. 5A,B), consistent with OLOO/OLO· interception by NO [29,30].

\subsection{Application 5: Enzymatic inhibition of lipid chain peroxidation in cells}

Another example of how $\left[{ }^{14} \mathrm{C}\right] \mathrm{ChOX}$ can accurately report on cellular chain peroxidation is represented in Fig. 6. This experiment tested the ability of GPx4, which catalyzes the GSH-dependent detoxification of $\mathrm{PLOOH}$ and $\mathrm{ChOOHs}$, to curtail damaging chain peroxidation induced by $7-\mathrm{OOH}$ bearing SUVs. As shown in Fig. 6A,B, transfectant clone $6 \mathrm{G} 4$ of $\mathrm{COH}-\mathrm{BR} 1$ cells (which overexpressed mitochondrial GPx4) accumulated $\left[{ }^{14} \mathrm{C}\right] \mathrm{ChOX}$ significantly slower than a vector control (VC), which, like wild type cells (not represented), expressed almost negligible GPx4 [21]. Other experiments with 6G4

vs. VC COH-BR1 cells showed that the former, in addition to being more resistant to chain peroxidation, were more resistant to a loss of mitochondrial membrane potential $\left(\Delta \Psi_{\mathrm{m}}\right)$ and to cell death via intrinsic apoptosis [21]. Thus, GPx4 inhibited damaging chain lipid peroxidation, but unlike NO or other chain-breaking antioxidants, did so by inactivating chain-initiating LOOHs [20,21].

\section{Notes and Precautions}

Protocols 1-4 involve the use of cholesterol radiolabeled with Carbon-14, which is a weak $\beta$-particle emitter. As true for all radioisotopes, precautions should be observed when purifying $\left[{ }^{14} \mathrm{C}\right]$ Cholesterol and inserting it into liposomal and cellular membranes and also when isolating $\left[{ }^{14} \mathrm{C}\right] \mathrm{ChOX}$ for HPTLC-PI analysis. Thus, protective gloves should be worn for these procedures in order to avoid skin contact 
with radioactive material. The light sources and photosensitizers used in Protocols 2 and 4 involve no obvious hazards when used as described.

\section{Summary and Conclusions}

We have described a straightforward new technique for monitoring free radical-mediated lipid peroxidation in cell membranes and lipoproteins whereby radiolabeled cholesterol is exploited as a natural lipid probe. Among the many attractive features of this approach are its relative simplicity and convenience, which should make it useful to investigators seeking better ways to monitor oxidative stress-induced lipid peroxidation. One can use this approach to accurately assess the chain-initiating potency of pre-existing or primary $\mathrm{PLOOH}$ and $\mathrm{ChOOHs} .\left[{ }^{14} \mathrm{C}\right] \mathrm{Ch}$ incorporated into a membrane or lipoprotein gives rise to $\left[{ }^{14} \mathrm{C}\right] \mathrm{ChOX}$ species, which are readily monitored by HPTLC-PI. These species, which include redox-active intermediates (e.g. $7 \alpha / \beta-O O H)$ as well as redox-inactive products $(7 \alpha / \beta-O H$, $7=0,5,6>0$ ), report on chain lipid peroxidation taking place in the vicinity of a primary hydroperoxide, and by implication, the oxidizability of surrounding lipids and availability of catalytic metal ions and reductants. There are several advantages of using $\left[{ }^{14} \mathrm{C}\right] \mathrm{Ch}$ as a probe lipid. First, $\mathrm{Ch}$ autoxidation has been studied extensively over the last 50 years and most of its important oxidation intermediates/products have been well characterized [7,8,31]. To a great extent, this reflects the fact that $\mathrm{Ch}$, unlike natural phospholipids, exists as a single molecular species, thus facilitating individual ChOX isolation and identification. Second, because our approach exploits $\mathrm{Ch}$ as a natural in situ probe, it avoids potential artifacts associated with use of exogenous probes such as spin traps [32] or fluorophores such as DPPP and C11-BODIPY [33,34]. Upon binding to a membrane or lipoprotein, such agents might alter responses by perturbing existing structure, thus potentially interfering with chain propagation. Of course, these concerns are at least partially offset by the advantage of directly analyzing intact cells rather than extracts of cellular lipids. Third, since most of the $\mathrm{Ch}$ in mature mammalian cells $(>80 \%)$ is located in the plasma membrane, $\left[{ }^{14} \mathrm{C}\right] \mathrm{Ch}$ would be an excellent probe for free radical activity occurring in this compartment, e.g. activity initiated by LOOHs from external ${ }^{1} \mathrm{O}_{2}$ attack or LOOHs translocated from other cells under greater oxidative pressure, e.g. red blood cells. Fourth, $\mathrm{Ch}$ is capable of spontaneous and reasonably rapid translocation from a donor membrane, e.g. 
unilamellar liposome, to an acceptor membrane or lipoprotein [23]. This makes $\left[{ }^{14} \mathrm{C}\right] \mathrm{Ch}$ labeling of acceptors for chain peroxidation assessment relatively convenient. Finally, $\left[{ }^{14} \mathrm{C}\right] \mathrm{Ch}$ gives rise to a relatively small number of $\left[{ }^{14} \mathrm{C}\right] \mathrm{ChOX}$ species, which are well resolved by HPTLC-PI and can be individually quantified, as described. In addition to assessing chain-initiating potency of a primary $\mathrm{ChOOH}$ or $\mathrm{PLOOH}$ by this approach, one can easily assess chain length by integrating $\left[{ }^{14} \mathrm{C}\right] \mathrm{ChOX}$ levels for any given reaction time, thus providing information that is not available when spin trap or fluorophore probes are used.

\section{Acknowledgements}

Research support from the following agencies is gratefully acknowledged: (i) USPHS Grants CA70823, CA72630, TW001386, and HL85677 (to AWG); (ii) NSF Grant MCB-9106117 (to AWG); (iii) Polish National Science Center Grant NZ3/00833 (to WK). 


\section{References}

[1] H. Sies, Biochemistry of oxidative stress, Angew. Chem. Int. Ed. Engl. 25 (1986) 1058-1071.

[2] N.A. Porter, S.E. Caldwell, K.A. Mills, Mechanisms of free radical oxidation of unsaturated lipids, Lipids 30 (1995) 277-290.

[3] B. Halliwell, J.M.C. Gutteridge, Free Radicals in Biology and Medicine, Clarendon Press, Oxford, UK, 1999.

[4] A.W. Girotti, Lipid hydroperoxide generation, turnover, and effector action in biological systems, J. Lipid Res. 39 (1998) 1529-1542.

[5] A.L. Wilcox, L.J. Marnett, Polyunsaturated fatty acid alkoxyl radicals exist as carbon-centered epoxyallylic radicals: a key step in hydroperoxide-amplified lipid peroxidation, Chem. Res. Toxicol. 6 (1993) 413-416.

[6] A.J. Brown, W. Jessup, Oxysterols: sources, cellular storage and metabolism, and new insights into their roles in cholesterol homeostasis, Mol. Aspects Med. 30 (2009) 111-122.

[7\} A.W. Girotti, Photosensitized oxidation of membrane lipids: reaction pathways, cytotoxic effects, and cytoprotective mechanisms, J. Photochem. Photobiol. B. 63 (2001) 103-113.

[8] R.C. Murphy, K.M. Johnson, Cholesterol, reactive oxygen species, and the formation of biologically active mediators, J. Biol. Chem. 283 (2008)15521-15525.

[9] A.W. Girotti, W. Korytowski, Cholesterol as a singlet oxygen detector in biological systems, Methods Enzymol. 319 (2000) 85-100.

[10] Y. Yamamoto, B. Frei, B.N. Ames, Assay of lipid hydroperoxides using high-performance liquid chromatography with isoluminal chemiluminescence detection, Methods Enzymol. 186 (1990) 371 380.

[11] W. Korytowski, P.G. Geiger, A.W. Girotti, High-performance liquid chromatography with mercury cathode electrochemical detection: application to lipid hydroperoxide analysis, J. Chromatogr. B. 670 (1995) 189-197.

[12] W. Korytowski, P.G. Geiger, A.W. Girotti, Lipid hydroperoxide analysis by high-performance liquid chromatography with mercury cathode electrochemical detection, Methods Enzymol. 300 (1999) 23-33.

[13] W. Korytowski, M. Wrona, A.W. Girotti, Radiolabeled cholesterol as a reporter for assessing oneelectron turnover of lipid hydroperoxides, Anal. Biochem. 270 (1999) 123-132.

[14] W. Korytowski, G.J. Bachowski, A.W. Girotti, Chromatographic separation and electrochemical determination of cholesterol hydroperoxides generated by photodynamic action, Anal. Biochem. 197 (1991)149-156.

[15] L.D. Mayer, M.J. Hope, P.R. Cullis, Vesicles of variable size produced by a rapid extrusion procedure, Biochim. Biophys. Acta 858 (1986) 161-168. 
[16] J.P.Thomas, B. Kalyanaraman, A.W. Girotti, Involvement of preexisting lipid hydroperoxides in $\mathrm{Cu}(2+)$-stimulated oxidation of low-density lipoprotein, Arch. Biochem. Biophys, 315 (1994) 244254.

[17] T. Miida, C.J. Fielding, P.E. Fielding, Mechanism of transfer of LDL-derived free cholesterol to HDL subfractions in human plasma, Biochemistry 29 (1990) 10469-10474.

[18] A. Vila, W. Korytowski, A.W. Girotti, Spontaneous transfer of phospholipid and cholesterol hydroperoxides between cell membranes and low-density lipoprotein: assessment of reaction kinetics and prooxidant effects, Biochemistry 41 (2002) 13705-13716.

[19] R.S. Esworthy, M.A. Baker, F.F. Chu, Expression of selenium-dependent glutathione peroxidase in human breast tumor cell lines, Cancer Res. 55 (1995) 957-962.

[20] J.P. Thomas, M. Maiorino, F. Ursini, A.W. Girotti, Protective action of phospholipid hydroperoxide glutathione peroxidase against membrane-damaging lipid peroxidation. In situ reduction of phospholipid and cholesterol hydroperoxides, J. Biol. Chem. 265 (1990) 454-461.

[21] R. Hurst, W. Korytowski, T. Kriska, R.S. Esworthy, F.F. Chu, A.W. Girotti, Hyperresistance to cholesterol hydroperoxide-induced peroxidative injury and apoptotic death in a tumor cell line that overexpresses glutathione peroxidase isotype-4, Free Radic. Biol. Med. 31 (2001) 1051-1065.

[22] A. Vila, W. Korytowski, A.W. Girotti, Dissemination of peroxidative stress via intermembrane transfer of lipid hydroperoxides: model studies with cholesterol hydroperoxides, Arch. Biochem. Biophys. 380 (2000) 208-218.

[23] A.W. Girotti, Translocation as a means of disseminating lipid hydroperoxide-induced oxidative damage and effector action, Free Radic. Biol. Med. 44 (2008) 956-968.

[24] W. Korytowski, M. Zareba, A.W. Girotti, Nitric oxide inhibition of free radical-mediated cholesterol peroxidation in liposomal membranes, Biochemistry 39 (2000) 6918-6928.

[25] W. Korytowski, M. Zareba, A.W. Girotti, Inhibition of free radical-mediated cholesterol peroxidation by diazeniumdiolate-derived nitric oxide: effect of release rate on mechanism of action in a membrane system, Chem. Res. Toxicol. 13 (2000) 1265-1274.

[26] T. Kriska, W. Korytowski, A.W. Girotti, Hyperresistance to photosensitized lipid peroxidation and apoptotic killing in 5-aminolevulinate-treated tumor cells overexpressing mitochondrial GPX4, Free Radic. Biol. Med. 33 (2002) 1389-1402.

[27] J.I. Teng, M.J. Kulig, L.L. Smith, G. Kan, J.E. Van Lier, Sterol metabolism. XX. Cholesterol 7 $\beta-$ hydroperoxide, J. Org. Chem. 38 (1973) 119-123.

[28] W. Korytowski, J.C. Schmitt, A.W. Girotti, Surprising inability of singlet oxygen-generated 6hydroperoxycholesterol to induce damaging free radical lipid peroxidation in cell membranes, Photochem. Photobiol. 86 (2010) 747-751. 
[29] M. Niziolek, W. Kowytowski, A.W. Girotti, Nitric oxide inhibition of free radical-mediated lipid peroxidation in photodynamically treated membranes and cells, Free Radic. Biol. Med. 34 (2003) 997-1005.

[30] M. Niziolek, W. Korytowski, A.W. Girotti, Chain-breaking antioxidant and cytoprotective action of nitric oxide on photodynamically stressed tumor cells, Photochem. Photobiol. 78 (200) 262-270.

[31] L.L. Smith, Cholesterol Autoxidation (1981) Plenum Press, New York.

[32] B.A. Wagner, G.R. Buettner, C.P. Burns, Free radical-mediated lipid peroxidation in cells: oxidizability is a function of cell lipid bis-allylic hydrogen content. Biochemistry 33 (1994) 44494453.

[33] M. Takahashi, M. Shibata, E. Niki, Estimation of lipid peroxidation of live cells using a fluorescent probe, diphenyl-1-pyrenylphosphine, Free Radic. Biol. Med, 31 (2001) 164-174.

[34] G.P. Drummen, L.C. van Liebergen, J.A. Op den Kamp, J.A. Post, C11-BODIPY(581/591), an oxidation-sensitive fluorescent lipid peroxidation probe: (micro)spectroscopic characterization and validation of methodology, Free Radic. Biol. Med, 33 (2002) 473-490. 


\section{Scheme and Figure legends}

Scheme 1. Flow diagram for labeling cells with $\left[{ }^{14} \mathrm{C}\right] \mathrm{Ch}$, applying an oxidative stress that induces free radical (chain) lipid peroxidation, and determining $\left[{ }^{14} \mathrm{C}\right] \mathrm{ChOX}$ species by HPTLC-PI.

Fig. 1. Structures of cholesterol hydroperoxides and other oxides referred to in this article. Formal names of these species are provided in the list of abbreviations.

Fig. 2. Time courses for $\left[{ }^{14} \mathrm{C}\right] \mathrm{ChOX}$ accumulation in liposomes as determined by HPTLC-PI. $\mathrm{POPC} /\left[{ }^{14} \mathrm{C}\right] \mathrm{Ch} / 5 \alpha-\mathrm{OOH}(1.0: 0.75: 0.05$ by mol) LUVs $(1.8 \mathrm{mM}$ total lipid in bulk phase PBS) were incubated at $37^{\circ} \mathrm{C}$ in the presence of $1 \mu \mathrm{M} \mathrm{Fe}(\mathrm{HQ})_{3}$ and $1 \mathrm{mM} \mathrm{AH}^{-}$. At the indicated times, lipids were extracted and analyzed by HPTLC-PI. (A) Chromatographic profiles of $\left[{ }^{14} \mathrm{C}\right] \mathrm{ChOX}$ species. Identities were based on co-migration of authentic standards (not shown). (B) Integrated band intensities: $7 \beta-$ $\mathrm{OOH}(\bullet), 7 \alpha-\mathrm{OOH}(\mathrm{o}), 7 \alpha-\mathrm{OH}(\boldsymbol{\Delta}), 7 \beta-\mathrm{OH}(\triangle), 5,6>\mathrm{O}(\square)$. A control without $\mathrm{AH}^{-}$, but with $\mathrm{Fe}(\mathrm{HQ})_{3}$ is also represented (+). Reproduced from Ref. 25 with permission.

Fig. 3. $\left[{ }^{14} \mathrm{C}\right] \mathrm{ChOX}$ accumulation during photoperoxidation of liposomes: inhibitory effects of NO. (A) POPC/ $\left[{ }^{14} \mathrm{C}\right] \mathrm{Ch} / \mathrm{PpIX}\left(100: 80: 0.2\right.$ by mol) LUVs were irradiated for $45 \mathrm{~min}\left(\sim 120 \mathrm{~J} / \mathrm{cm}^{2}\right.$ light fluence $)$ in the presence of $1 \mu \mathrm{M} \mathrm{Fe}(\mathrm{HQ})_{3}$ and $1 \mathrm{mM} \mathrm{AH}^{-}$(lane 3) or $1 \mu \mathrm{M} \mathrm{Fe}(\mathrm{HQ})_{3}, 1 \mathrm{mM} \mathrm{AH}^{-}$, and $0.2 \mathrm{mM}$ SPNO (lane 4). Also represented is a dark control with $\mathrm{Fe}(\mathrm{HQ})_{3} / \mathrm{AH}^{-}$(lane 1) and a light control without $\mathrm{Fe}(\mathrm{HQ})_{3} / \mathrm{AH}^{-} / \mathrm{SPNO}$ (lane 2). (B) $5 \alpha-\mathrm{OH}(\mathrm{o}, \bullet)$ and $6 \beta-\mathrm{OH}(\square, \boldsymbol{\bullet})$ buildup with increasing light fluence. (C) $7 \alpha-\mathrm{OH}(\triangle, \mathbf{\Lambda})$ and $7 \beta-\mathrm{OH}(\nabla, \boldsymbol{\nabla})$ buildup with increasing light fluence. Irradiation was carried out in the absence (open symbols) or presence (closed symbols) of $0.2 \mathrm{mM}$ SPNO. Plotted data are means \pm deviation of values from duplicate experiments. Reproduced from Ref. 28 with permission.

Fig. 4. $\left[{ }^{14} \mathrm{C}\right] \mathrm{ChOX}$ accumulation in transfer LOOH-enriched LDL. $\left[{ }^{14} \mathrm{C}\right] \mathrm{Ch}$-labeled LDL $(2.5 \mathrm{mM}$ lipid; $\sim 0.5 \mu \mathrm{Ci} / \mathrm{ml}$ ) was incubated with photoperoxidized erythrocyte ghosts $(0.25 \mathrm{mM}$ lipid; $75 \mu \mathrm{M}$ PLOOH plus $\mathrm{ChOOH}$ ) for $1.5 \mathrm{~h}$ in argon-sparged PBS at $37^{\circ} \mathrm{C}$. After centrifugation, LDL was recovered, diluted 
4-fold in PBS, and incubated in the presence of $20 \mu \mathrm{M} \mathrm{CuCl}_{2}$. A control that had been treated with non-photoperoxidized ghosts was incubated alongside. Samples were recovered at various times up to $4 \mathrm{~h}$, extracted, and lipid fractions subjected to HPTLC-PI analysis. (A) $\left[{ }^{14} \mathrm{C}\right] \mathrm{ChOX}$ profiles as a function of incubation time for System a (control LDL) and System b (LOOH-exposed LDL). Sample load: $\sim 0.1$ $\mu$ g lipid per lane. (B) Time courses for total ChOX accumulation: $(\triangle)$ System a; $(\circ)$ System b. Data are from the same experiment as in panel (A) with additional time points represented. The plots show ChOX concentrations in bulk reaction mixtures. Reproduced from Ref. 18 with permission.

Fig. 5. Effects of NO on ChOX accumulation in cells subjected to a photodynamic challenge. $\left[{ }^{14} \mathrm{C}\right] \mathrm{Ch}-$ labeled $\mathrm{COH}-\mathrm{BR} 1$ cells were treated with $\mathrm{ALA}$ alone or $\mathrm{ALA}$ plus $\mathrm{Fe}(\mathrm{HQ})_{3}$, then irradiated for 30 min in the absence or presence of $0.4 \mathrm{mM}$ SPNO (added immediately before irradiation). After $1 \mathrm{~h}$ of dark incubation, lipids were extracted and analyzed by HPTLC-PI. (A) $\left[{ }^{14} \mathrm{C}\right] \mathrm{ChOX}$ profiles showing origin (O), $7 \alpha-\mathrm{OH}(1), 7 \beta-\mathrm{OH}(2), 5 \alpha-\mathrm{OH}(3), 5,6>\mathrm{O} / 6-\mathrm{OOH}$ (4), $7-\mathrm{OOH} / 5 \alpha-\mathrm{OOH}$ (5), Ch (6), and cholesteryl esters (7), and solvent front $(F)$. Each lane represents lipid from $\sim 5 \times 10^{6}$ cells. Lane a: $A L A / F e(H Q)_{3}$ dark

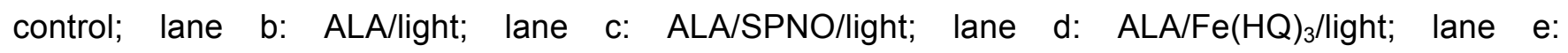
$\mathrm{ALA} / \mathrm{Fe}(\mathrm{HQ})_{3} / \mathrm{SPNO} /$ light. (B) ChOX yields as percentages of total radioactivity in each sample lane; values were background-corrected. $\mathrm{ChOOH}$ denotes unresolved $7 \alpha / 7 \beta-\mathrm{OOH}$ and $5 \alpha-\mathrm{OOH}$. Means \pm deviation of values from duplicate experiments are plotted. ${ }^{*} \mathrm{P}<0.005$ vs. ALA/light; ${ }^{* *} \mathrm{P}<0.001$ vs. ALA/ $\mathrm{Fe}(\mathrm{HQ})_{3} /$ light. Reproduced from Ref. 29 with permission.

Fig. 6. Effect of GPx4 overexpression on $\mathrm{ChOOH}$-induced chain peroxidation in tumor cells. A GPx4overexpressing clone (6G4) of $\mathrm{COH}-\mathrm{BR} 1$ cells and a vector control (VC) were labeled with $\left[{ }^{14} \mathrm{C}\right] \mathrm{Ch}$ by incubating with a $\left[{ }^{14} \mathrm{C}\right] \mathrm{Ch}-\mathrm{BSA}$ complex $(1: 15 \mathrm{~mol} / \mathrm{mol})$. The labeling strength for both cell types was approximately the same. Labeled cells were incubated for $1 \mathrm{~h}$ or $2 \mathrm{~h}$ with non-peroxidized (control) or photoperoxidized DMPC/Ch (1.0/0.8 by mol) SUVs. The initial 7-OOH concentration in the latter system was $\sim 150 \mu \mathrm{M}$. After incubation, cells were washed, harvested, and extracted; lipid fractions were analyzed by HPTLC-PI. (A) $\left[{ }^{14} \mathrm{C}\right]$ ChOX profiles. (B) Percent yields of various $\left[{ }^{14} \mathrm{C}\right] \mathrm{ChOX}$ species. 
Means \pm deviation of values from duplicate experiments are plotted. Reproduced from Ref. 21 with permission. 
Fig. 1
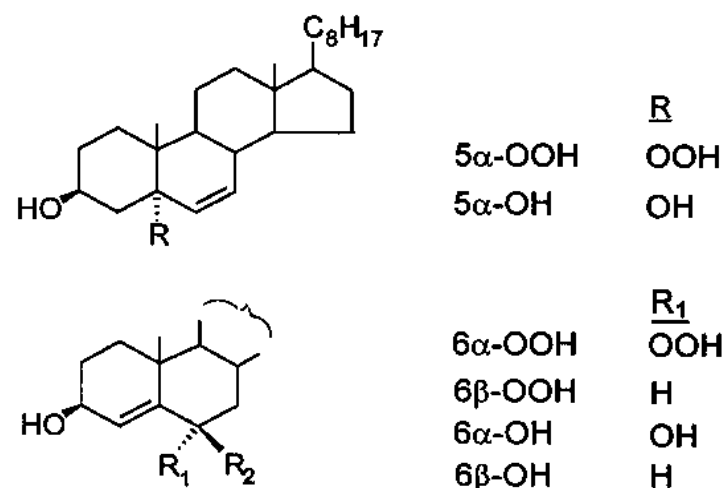

$\begin{array}{lll}6 \alpha-\mathrm{OOH} & \frac{\mathrm{R}_{1}}{\mathrm{OOH}} & \frac{\mathrm{R}_{2}}{\mathrm{H}} \\ 6 \beta-\mathrm{OOH} & \mathrm{H} & \mathrm{OOH} \\ 6 \alpha-\mathrm{OH} & \mathrm{OH} & \mathrm{H} \\ 6 \beta-\mathrm{OH} & \mathrm{H} & \mathrm{OH}\end{array}$

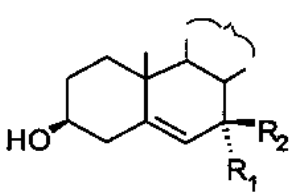

$\begin{array}{lll}7 \alpha-\mathrm{OOH} & \frac{\mathrm{R}_{1}}{\mathrm{OOH}} & \frac{\mathrm{R}_{2}}{\mathrm{H}} \\ 7 \beta-\mathrm{OOH} & \mathrm{H} & \mathrm{OOH} \\ 7 \alpha-\mathrm{OH} & \mathrm{OH} & \mathrm{H} \\ 7 \beta-\mathrm{OH} & \mathrm{H} & \mathrm{OH}\end{array}$

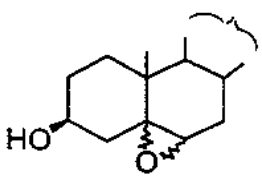

5,6-epoxide

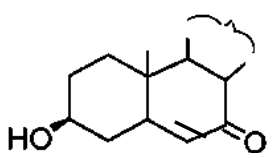

\section{7-ketone}


Fig.
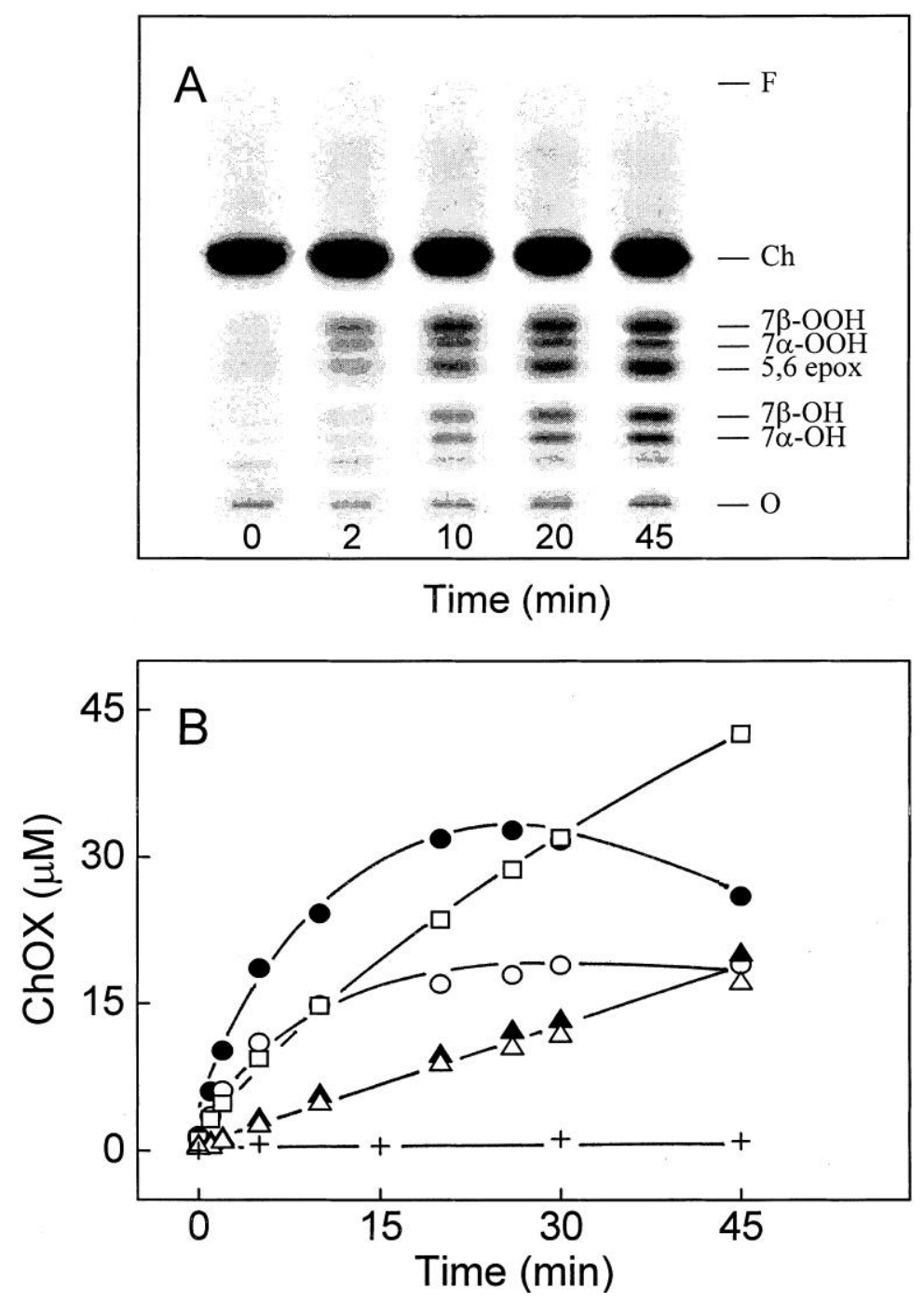
Fig.
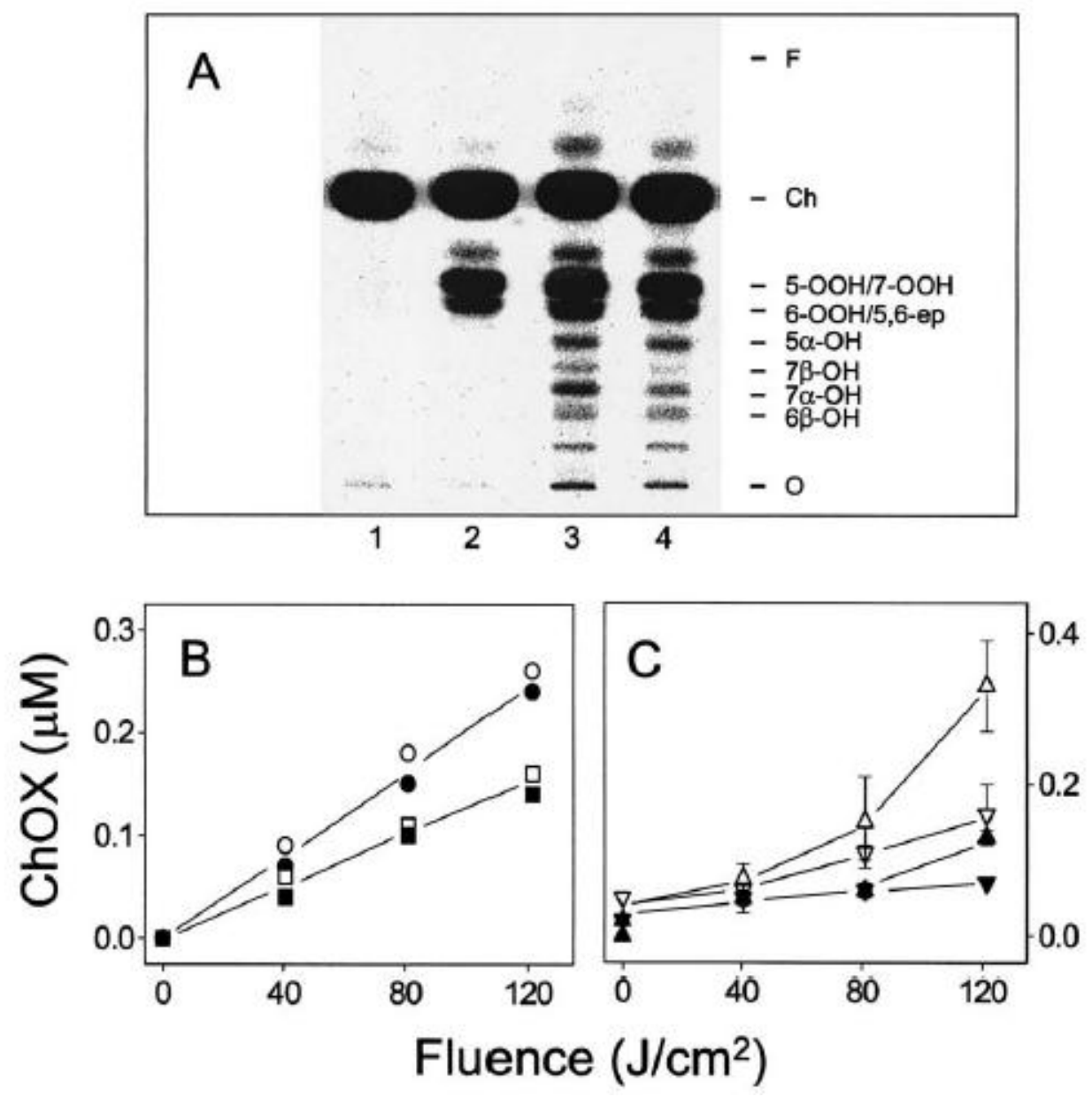
Fig.
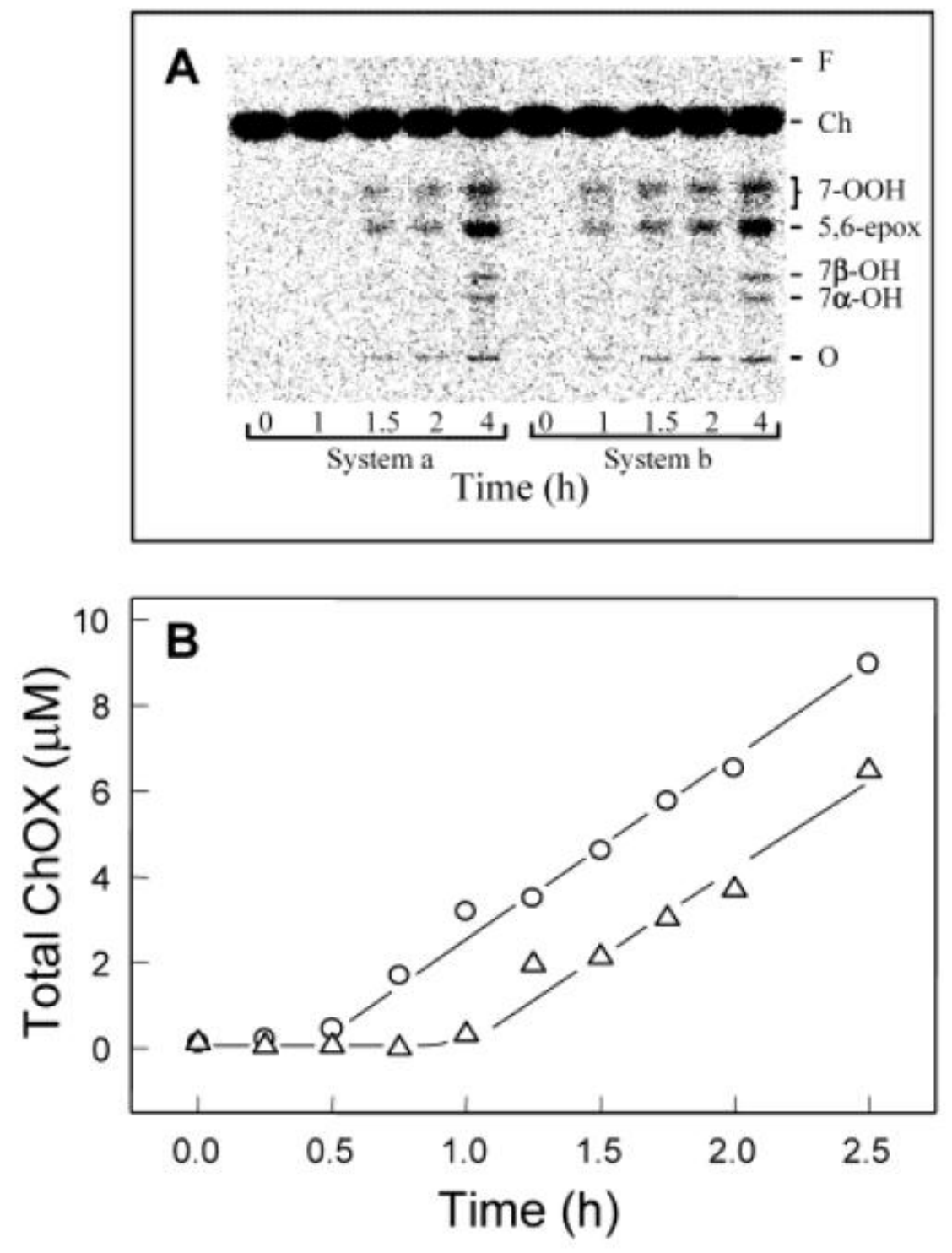
Fig.
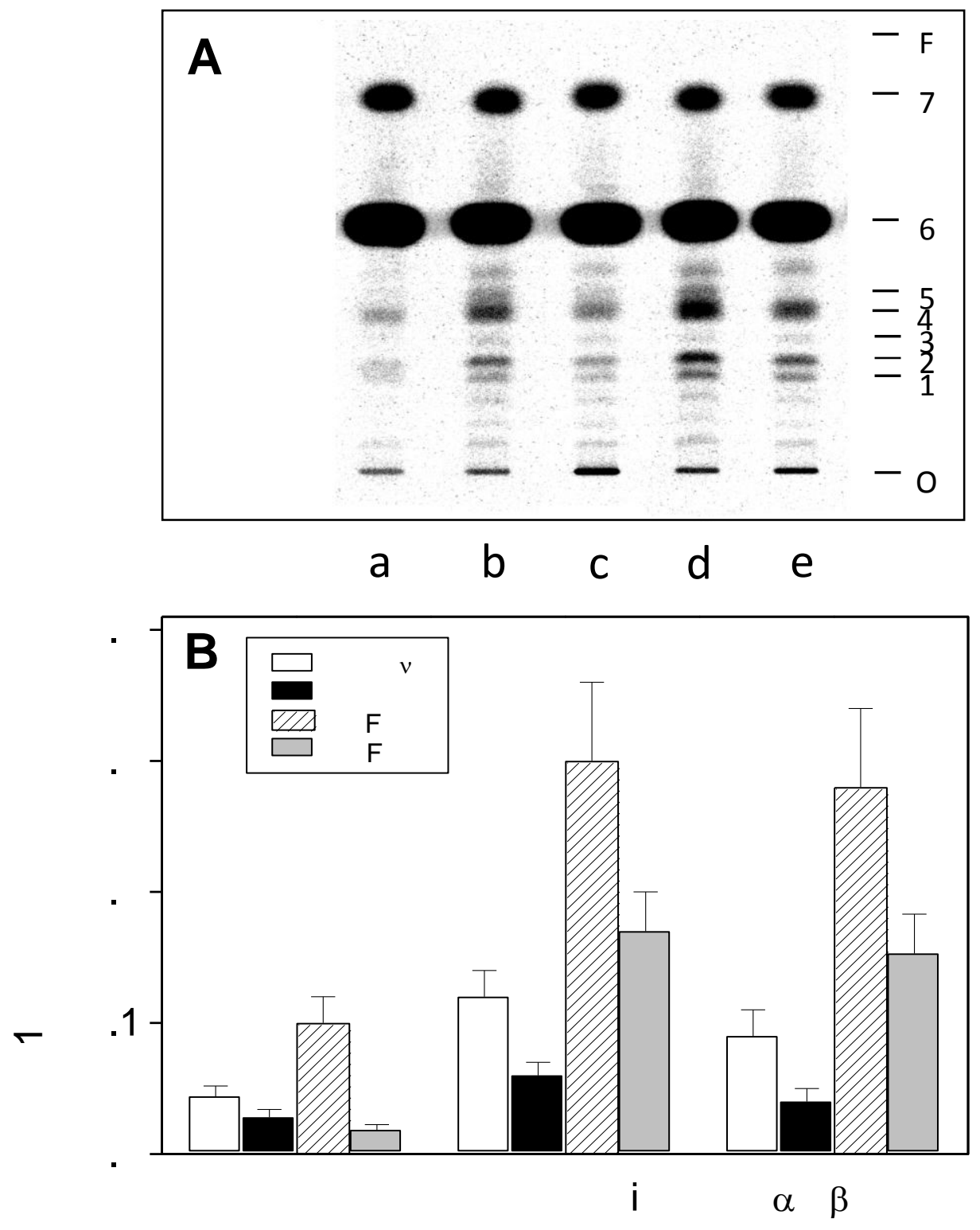
Fig.
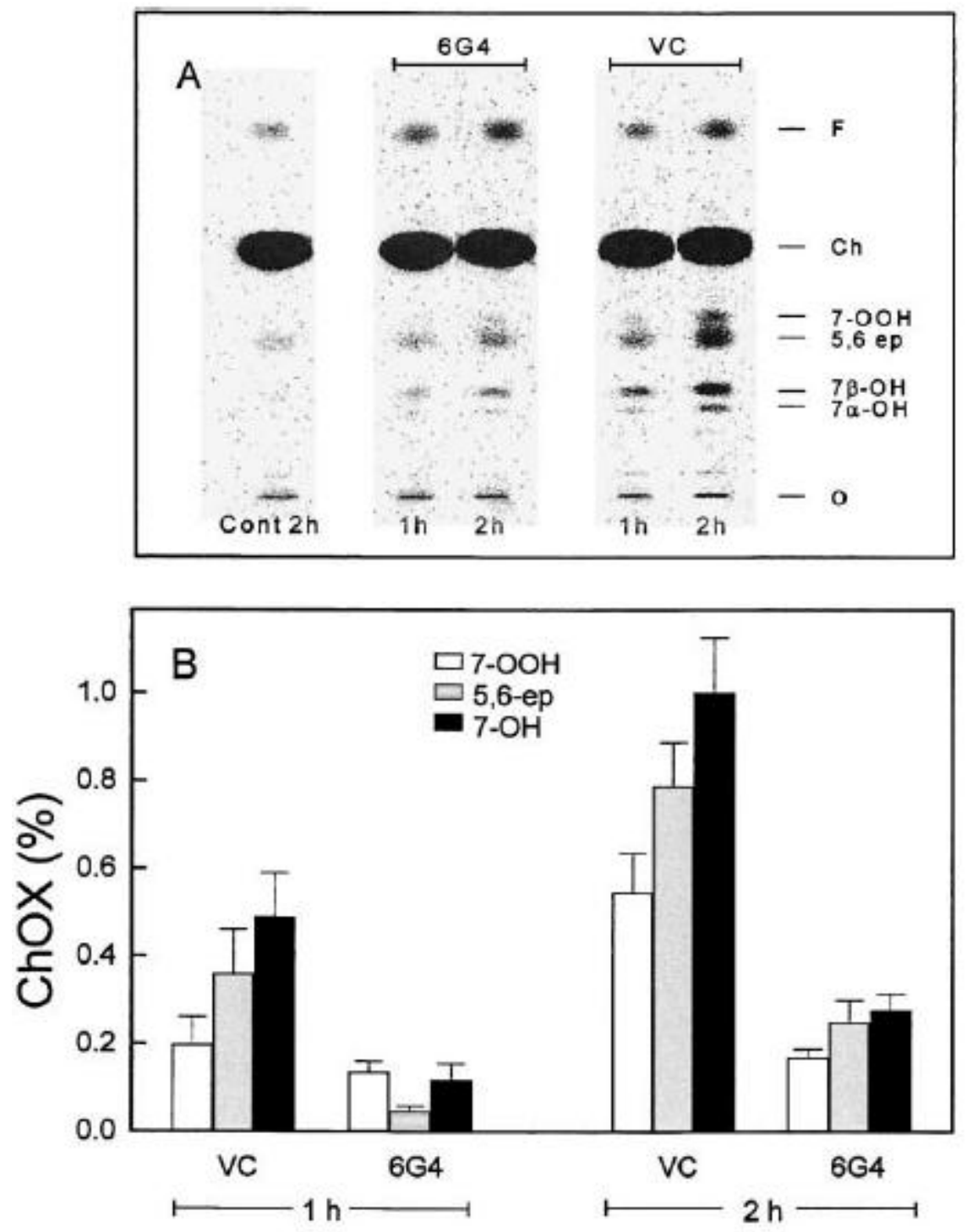


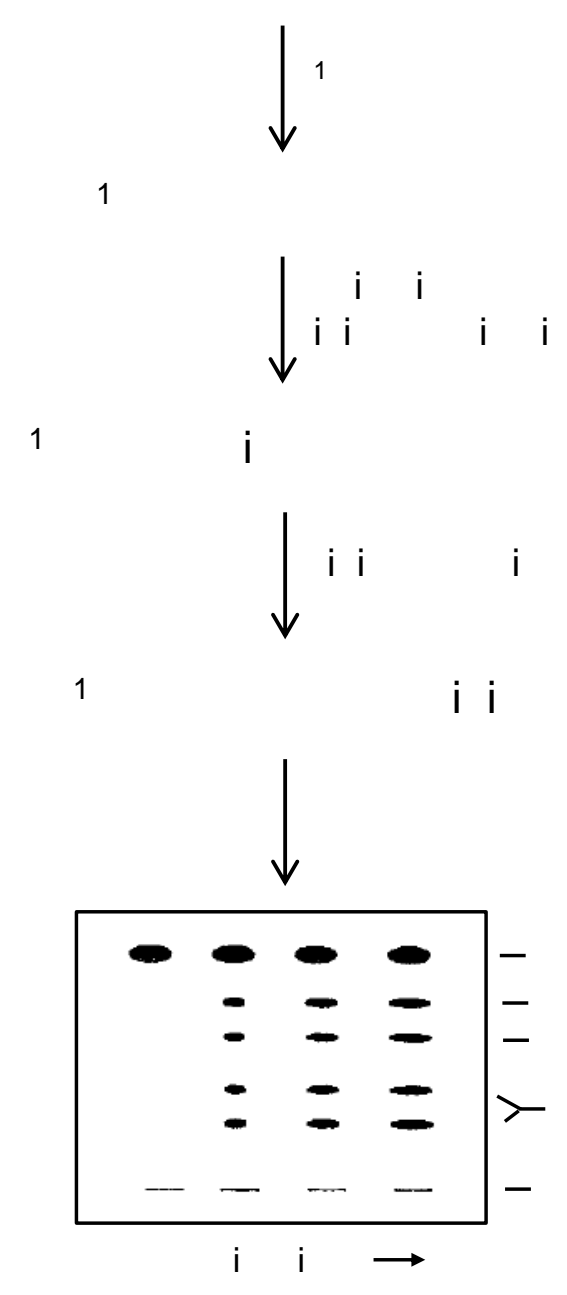

